\title{
A thank you to Dr Nicolle, a welcome to Dr Conly and a new chapter for The Canadian Journal of Infectious Diseases \& Medical Microbiology
}

\author{
Robert B Kalina, Publisher
}

\begin{abstract}
$\mathrm{T}^{\mathrm{h}}$ he year 2009 will mark many milestones for The Canadian Journal of Infectious Diseases $\mathcal{E}$ Medical Microbiology. We will celebrate the 20th Anniversary of the Journal and Dr Lindsay Nicolle's role as Editor-in-Chief. It will also mark the completion of Dr Nicolle's term and the beginning for our new Editor-in-Chief. On behalf of Pulsus Group, I would like to express our heartfelt thanks and recognition of the enormous amount of work and dedication that Dr Nicolle has infused into the Journal over the years.

At the same time, we are also grateful that Dr John Conly has agreed to take on what promises to be the difficult but rewarding role of Editor-in-Chief. Dr Conly has been a distinguished member of The Canadian Journal of Infectious Diseases \& Medical Microbiology Editorial Board (Section Editor) for many years. He is a Professor and the Head of the Department of Medicine at the University of Calgary and in the Calgary Health Region. He is trained as a specialist in Infectious Diseases and is a founding Co-Chair of the Canadian Hospital Epidemiology Committee, former President of the Canadian Infectious Disease Society and is the former Chairman of the Canadian Committee on Antibiotic Resistance. He has published over 150 papers and has received numerous honours, including a Distinguished Service Award from the Canadian
\end{abstract}

Infectious Diseases Society. Dr Conly possesses the powerful combination of expertise, creativity, tenacity and enthusiasm, which will be necessary to move the Journal forward.

Pulsus Group is also celebrating its 25th Anniversary in 2009. We have had 25 years of successfully publishing many Canadian medical peer-review journals, often utilizing the profits of one title to offset the losses in another. The Canadian Journal of Infectious Diseases $\mathcal{E}$ Medical Microbiology, unfortunately, falls into the latter category. When launched in 1990 as the third Pulsus journal, it was hailed as an important step in publishing research in this critical therapeutic area. While its contents provide the latest in infectious disease research, society guidelines, reviews, case reports, etc, and its readership goes well beyond the specialists, there has never been strong enough advertising support to make the Journal profitable.

Pulsus Group is committed to doing everything in our power to support all of our journals and will continue to explore all possible avenues to find a financial model that will support the Journal well into the future. We welcome Dr Conly's energy, creative thinking and commitment to excellence and look forward to working with him to bring new and innovative ideas for the Journal to fruition. 


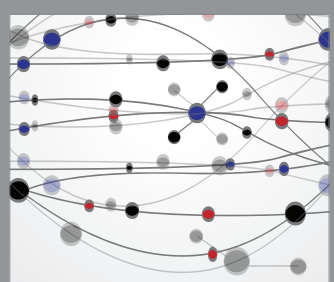

The Scientific World Journal
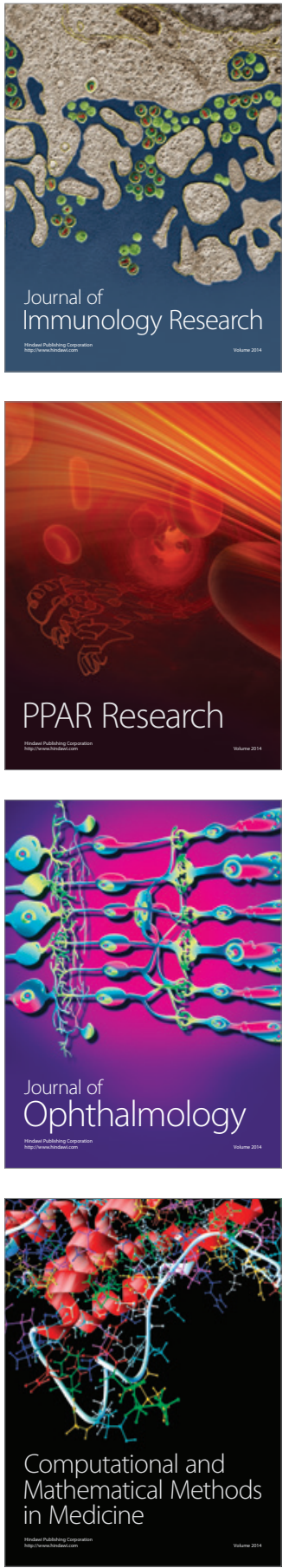

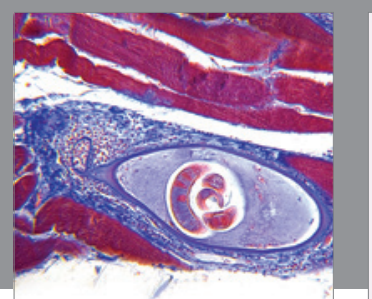

Gastroenterology Research and Practice

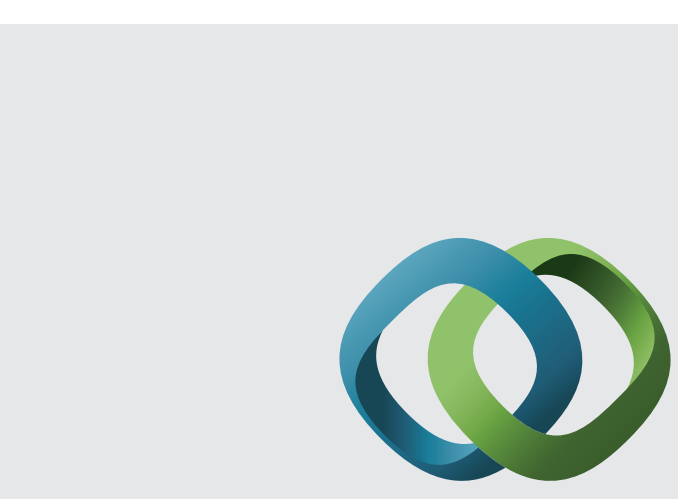

\section{Hindawi}

Submit your manuscripts at

http://www.hindawi.com
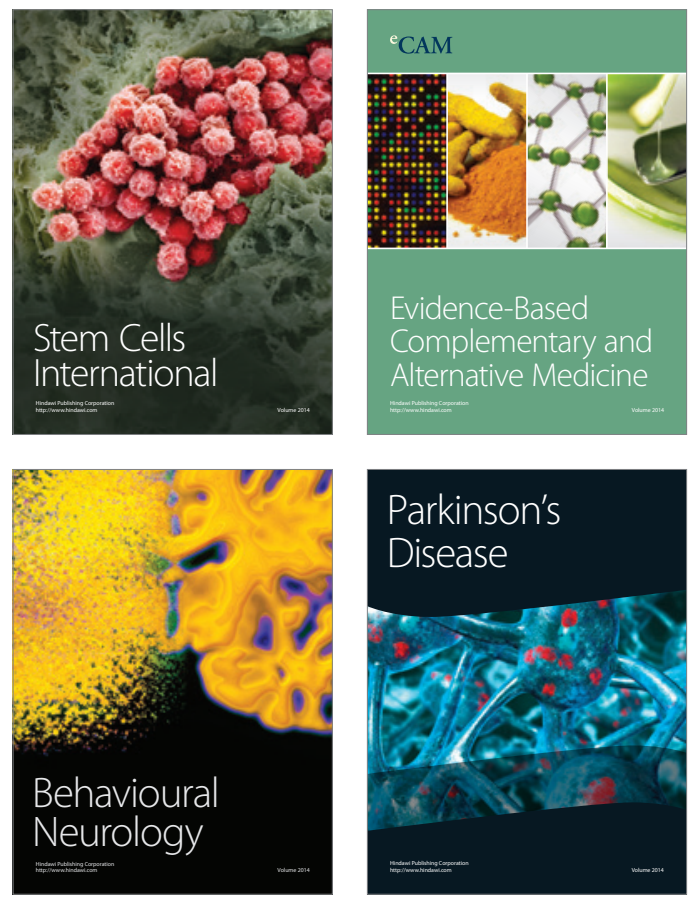
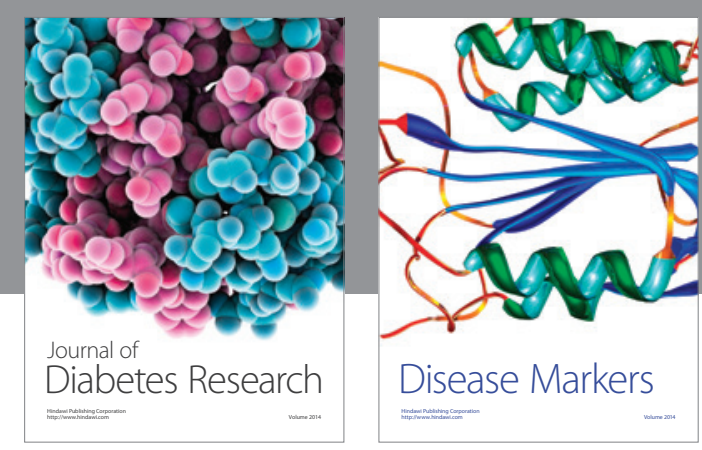

Disease Markers
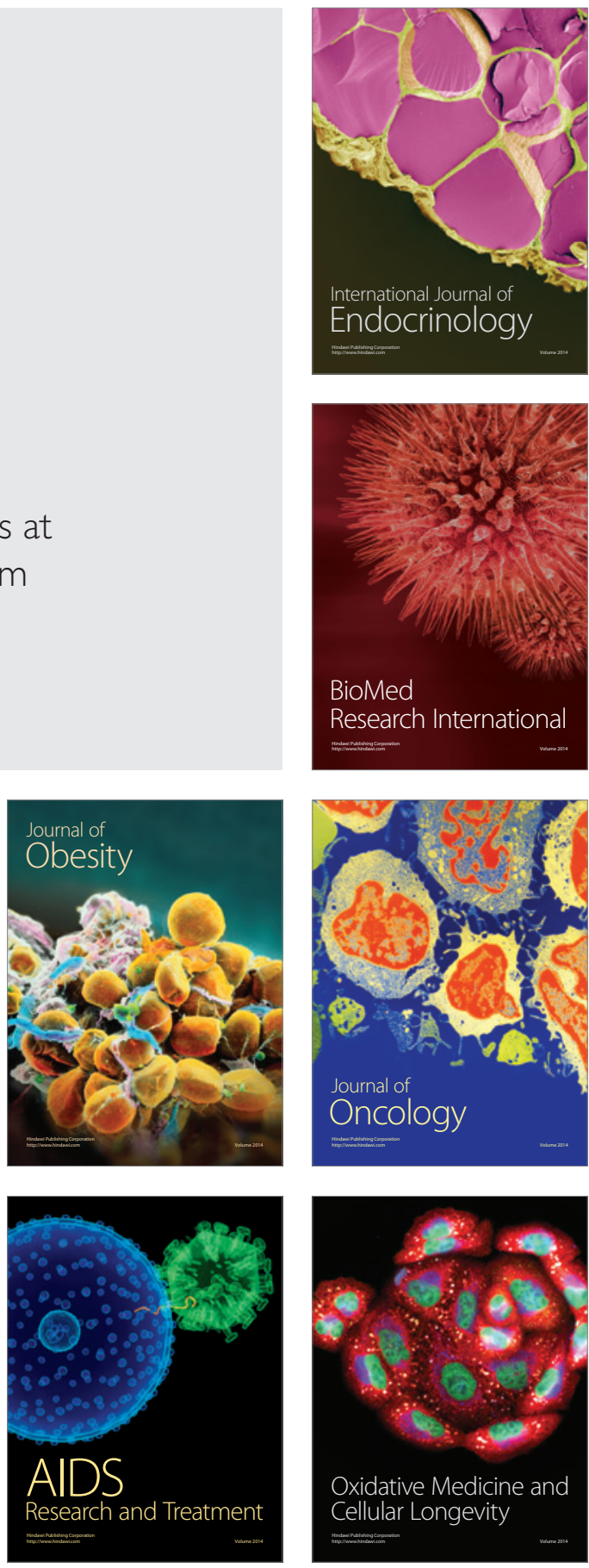